\title{
Modelo de Tomada de Decisão de Kortland no Delineamento de Atividade Didática para o Ensino de Bioquímica
}

\author{
Daniel Gedder Silva*, Vivane Lopes Leal, Fernanda Canduri e Salete Linhares Queiroz
}

Instituto de Química de São Carlos da Universidade de São Paulo

* Autor para correspondência: danielgedder@iqsc.usp.br

\begin{abstract}
RESUMO
A aplicação da metodologia de estudo de casos no ensino de ciências tem sido alvo de atenção de vários educadores nos últimos anos. No presente trabalho, relatamos a aplicação de uma atividade didática dessa natureza em disciplina de Bioquímica, oferecida no curso de Bacharelado em Química do Instituto de Química de São Carlos, da Universidade de São Paulo. Para que a atividade fosse levada a cabo fez-se necessária, inicialmente, a produção de um caso investigativo, denominado $O$ Mal do Século, que aborda a obesidade infantil. A resolução do caso foi apresentada pelos alunos no formato de relatório, cujo roteiro foi construído com base no Modelo de Tomada de Decisão de Kortland (1996). Nessa perspectiva, os estudantes pesquisaram e analisaram múltiplas fontes de dados fazendo uso de critérios desenvolvidos por eles para solucionar o caso.
\end{abstract}

Palavras-chave: Estudo de Caso; Ensino de Bioquímica; Obesidade Infantil.

\begin{abstract}
The use of case-study method in science education has been the focus of attention of many educators in recent years. In this work we describe a didactic activity based on this method in a biochemistry discipline offered to undergraduate chemistry students at the São Carlos Institute of Chemistry, University of São Paulo. Thus, we developed an investigative case entitled The Plague of the Century, which addresses childhood obesity. In order to solve the case, the students wrote a formal report according to the script produced by us, based on Kortland's Model of a Decision-making Procedure (1996). In view of this, the students researched and evaluated multiple sources of data, using criteria developed by them to solve the case.
\end{abstract}

Keywords: Case-Study; Teaching Biochemistry; Childhood Obesity.

\section{Introdução}

A aplicação da metodologia de estudo de caso, uma variante da Aprendizagem Baseada em Problemas (ABP), é apontada como vantajosa por educadores e com potencialidade para fomentar as habilidades argumentativas dos alunos e favorecer a aprendizagem do conteúdo científico. Além disso, a troca de ideias e a construção de conhecimentos que permeiam as atividades que conduzem à resolução de um determinado caso investigativo contribuem para a formação de um alunado crítico (SÁ \& QUEIROZ, 2010).

Nessa perspectiva, a solicitação de resolução de casos de caráter sociocientífico tem se difundido no Brasil, especialmente no ensino superior de
Química, a partir de ações desencadeadas por membros do Grupo de Pesquisa em Ensino de Química do Instituto de Química de São Carlos (GPEQSSG), da Universidade de São Paulo (USP) ${ }^{1}$.

No ensino de Bioquímica, até onde se sabe, é pouco recorrente na literatura nacional a aplicação de casos investigativos no Ensino Superior. Em contraponto, tais aplicações são relatadas com maior frequência no âmbito internacional. A título de exemplo citamos o trabalho de Cornely (1998), o qual relata as atividades realizadas por um grupo de estudantes de graduação em Bioquímica que foi solicitado a resolver um estudo de caso com base em exames médicos de um paciente com doença metabólica hereditária. A solução apontada deveria 
contemplar explicações sobre os sintomas do paciente e sugestões para o seu tratamento.

No presente trabalho, relatamos uma proposta de ensino dessa natureza e destacamos a realização de uma atividade, vinculada à resolução de um caso investigativo, que se pauta no Modelo de Tomada de Decisão de Kortland (1996). A utilização do referido modelo se mostrou conveniente no contexto da proposta, uma vez que o desenvolvimento da capacidade de tomada de decisão dos alunos se constitui em um dos propósitos almejados a partir da sua aplicação. Acreditamos que o alcance do pleno exercício das habilidades previstas para o profissional que atua na área de Bioquímica envolve o desenvolvimento de tal capacidade.

\section{Contexto de Aplicação da Proposta}

A metodologia de estudo de caso foi aplicada na disciplina SQM0416-Bioquímica II, ministrada no curso de Bacharelado em Química do Instituto de Química de São Carlos (IQSSC), da USP. Conforme consta no sistema de graduação da Universidade (Sistema Júpiter), o seu objetivo é complementar o estudo de conteúdos tratados na disciplina de SQM414-Bioquímica I, a partir da abordagem de princípios gerais do metabolismo celular e da biologia molecular.

Para que a proposta de ensino fosse colocada em funcionamento, fez-se necessária, inicialmente, a produção de um caso investigativo, denominado O Mal do Século, que aborda a obesidade infantil como tema central e foi redigido de acordo com as recomendações de Herreid (1997). Os alunos receberam o texto do caso e tomaram conhecimento da situação vivenciada pelos primos Fernando e Rafael, detentores de obesidade mórbida, assim como seus pais. A médica Carla, responsável pelo tratamento de ambos, tem ciência de que eles são membros da mesma família altamente consanguínea e solicitou vários exames com o intuito de sugerir um tratamento adequado. Na última consulta, com base nos resultados de exames relacionados aos níveis séricos de leptina, ela afirmou que a doença de Fernando não tem cura. Os alunos foram convidados a inves- tigar o problema de obesidade dos primos e propor formas seguras e eficazes para a cura do mal.

Cabe destacar que a proposta de ensino foi desenvolvida no âmbito da disciplina de pós-graduação oferecida pelo IQSG, SQF5798-Aspectos Avançados da Docência no Ensino Superior de Química, ministrada por uma das autoras do presente artigo. Outras propostas reportadas na literatura também se vinculam a essa disciplina e ao suporte que ela fornece a pós-graduandos, enquanto estagiários do Programa de Aperfeiçoamento de Ensino (PAE) da USP, na aplicação de atividades didáticas nos cursos de graduação (MASSI et al., 2013; TEODORO et al., 2011).

A classe foi dividida em nove grupos de três a cinco membros que deveriam solucionar o caso. Com o intuito de incentivar os alunos na busca pela sua resolução, duas modalidades de avaliação foram estabelecidas no segundo bimestre: prova escrita individual, perfazendo o valor de 7,5 pontos, e atividade didática envolvendo a produção de relatório em grupo, no qual deveria constar a resolução do caso, perfazendo o valor de 2,5 pontos.

O Modelo de Tomada de Decisão de Kortland (1996), apresentado no tópico a seguir, subsidiou a estruturação de um roteiro que foi construído com o propósito de auxiliar os alunos na redação do relatório.

\section{Modelo de Tomada de Decisão de Kortland e o Caso Investigativo O Mal do Século}

No artigo intitulado "An STS Case Study About Students' Decision Making on the Waste Issue", consta o Modelo de Tomada de Decisão de Kortland (1996), ilustrado na Figura 1. Este foi utilizado como referencial para a produção de um roteiro no qual existem questões que, uma vez respondidas pelos alunos, apresentam potencial para facilitar a tomada de decisão por parte deles quanto às soluções apontadas como mais adequadas para o caso investigativo O Mal do Século.

Segundo Sá (2010), no Modelo de Tomada de Decisão de Kortland (1996),

Os critérios para avaliar as soluções alternativas (ou as características desejáveis de uma solução) são 


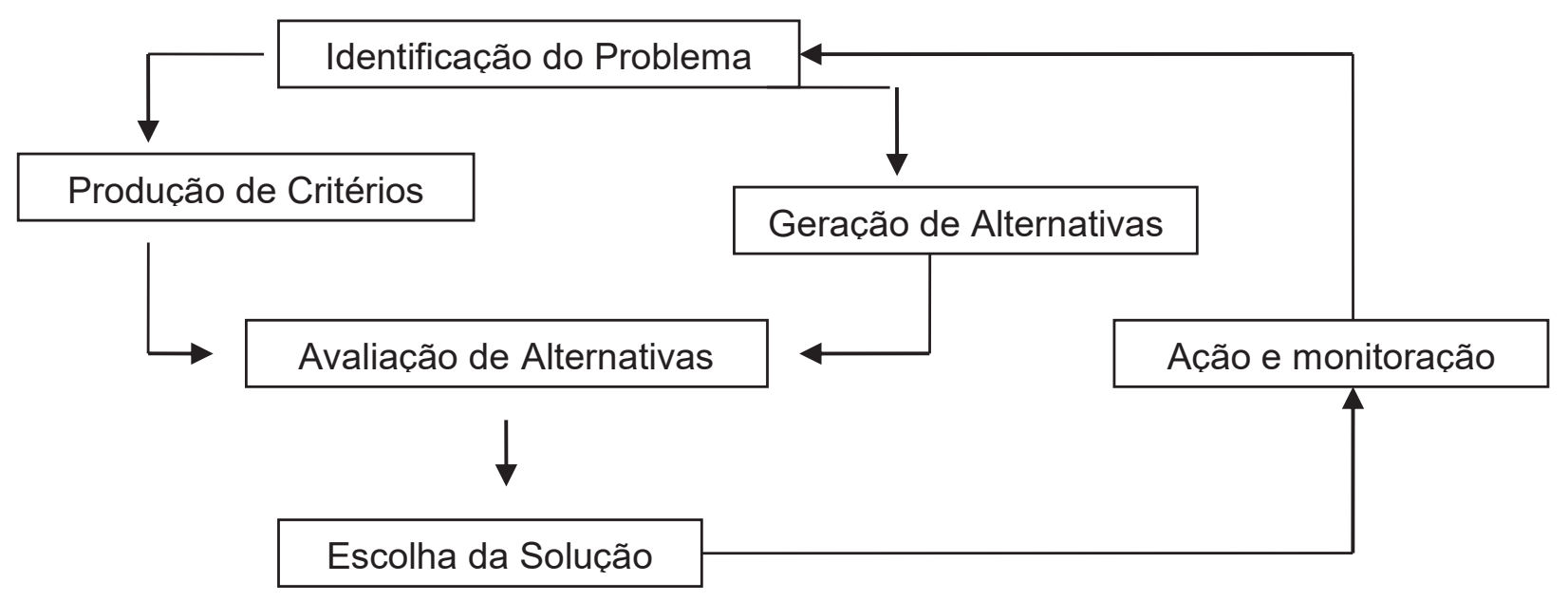

Figura 1 - Modelo de Tomada de Decisão de Kortland (1996).

formulados em direta conexão com a identificação do problema. As soluções alternativas geradas são avaliadas em um estágio posterior de acordo com esses critérios, resultando em uma decisão sobre o que parece ser a melhor ou a pior solução. E, finalmente, esses critérios são usados para monitorar os efeitos da decisão tomada: a solução escolhida teve os efeitos desejados na prática? Assim, esse modelo tem como um dos seus principais objetivos ensinar os estudantes a tomar decisões independentemente e de maneira reflexiva, comparando sistematicamente os prós e contras das possíveis alternativas de solução (SÁ, 2010, p. 76).

Na medida do possível, todas as questões/solicitações que constam do roteiro para redação de relatório sobre a resolução do caso investigativo Mal do Século contemplam elementos presentes no Modelo de Kortland (1996), conforme ilustra o Quadro 1. Dessa maneira, a primeira questão foi elaborada tendo em vista a identificação do problema existente no caso. A segunda questão, por sua vez, busca fomentar o processo de produção de critérios pelos alunos por meio da análise das características diversas envolvidas no caso. A terceira e a quarta questão estão relacionadas, respectivamente, à geração e à avaliação das alternativas. Os itens posteriores dizem respeito à escolha da melhor solução e à ação.

\section{Relatórios Produzidos sobre Resolução do Caso Investigativo O Mal do Século}

A partir da resolução das questões propostas no Quadro 1, os grupos de alunos tomaram suas decisões e apontaram resoluções para o caso investigado. Foram oferecidas respostas de três naturezas distintas, categorizadas da seguinte forma:

a) Respostas que indicam possibilidades de melhoras de saúde para ambos os primos, com sugestão de tratamento com injeções de leptina para Fernando e alimentação saudável e exercícios físicos para Rafael. O trecho, a seguir, ilustra uma resposta incluída neste grupo:

O caso de Fernando pode ter cura. De acordo com pesquisas realizadas recentemente, quando se injeta leptina em indivíduos ob/ob (genes ob defeituosos) eles perdem peso. No caso de Rafael, [...] por estar em fase de desenvolvimento, seu quadro de obesidade pode ser revertido pelo controle de sua alimentação e pela prática de atividades físicas.

b) Respostas que modificam um pouco a perspectiva citada no item anterior, a partir da indicação de medicamentos também para o caso de Rafael, conforme ilustra o trecho a seguir:

Rafael possui obesidade passível de cura apenas seguindo uma rotina de exercícios físicos, 


\section{1) Identificação do problema}
a) Assunto:

Explicar em linhas gerais o assunto do caso e fazer um levantamento do que é necessário para solucioná-lo.

\section{2) Produção de critérios}

b) Pesquisa das características do problema:

Quais os vínculos científicos que o caso apresenta? Seguem alguns exemplos: enzimas - função e propriedades; metabolismo de carboidratos; glicose; bioenergética; lipídeos e membranas biológicas.

c) Julgamento de valor - gravidade do problema:

Fazer um julgamento da gravidade do problema descrito no caso. Justificar a resposta.

\section{3) Geração de alternativas}

d) Inventário de medidas:

Quais diferentes tipos de medidas normalmente são tomados diante da situação apresentada?

Qual a causa e origem da obesidade de Fernando e de Rafael a nível biomolecular?

Será realmente que a obesidade de Fernando não tem cura?

Por que a endocrinologista fez exames para avaliar os níveis séricos de leptina?

Quais são os fatores biomoleculares envolvidos no processo de desenvolvimento da obesidade?

\section{4) Avaliação das alternativas}

e) Pesquisa das características das medidas:

As medidas acima citadas são suficientes para resolver o problema?

Que outras medidas importantes deveriam ser tomadas?

\section{5) Escolha da solução}

f) Julgamento de valores da melhor solução:

Quais medidas são mais adequadas para a resolução do caso?

Explicar as vantagens e desvantagens das opções escolhidas em relação a outras possíveis soluções.

\section{6) Ação}

\section{g) Estabelecimento de um plano de ação:}

Apresentem a medida que vocês julgaram mais adequada para a resolução do problema de Fernando e Rafael.

h) Execução da decisão.

\section{7) Conclusão}

Quadro 1 - Roteiro para Redação de Relatório sobre Resolução do Caso Investigativo.

dieta balanceada e ajudada por remédios inibidores de lipase. Diferente do que afirmou a endocrinologista, o caso de Fernando também tem cura, pois a injeção de leptina em indivíduos cujo gene ob apresenta mutação traz resultados satisfatórios.

c) Respostas que indicam a não possibilidade de cura para Fernando, como mostra este trecho:
O caso de Fernando é, sim, irreversível, pois o mesmo apresenta um defeito genético, que faz com que ele produza quantidades insuficientes de leptina. O caso de Rafael é reversível, pois se trata, com certeza, de hábitos alimentares inadequados.

A análise dos relatórios também indicou a ampla quantidade e variedade de conhecimentos de 
Bioquímica mobilizados na construção das resoluções para o caso. As notas atribuídas pelo docente corroboram o bom desempenho da maioria dos alunos: apenas dois grupos obtiveram nota inferior a 2,0 pontos, sendo que a nota máxima era 2,5 . Em contraponto, poucas são as considerações existentes nos relatórios sobre aspectos sociais e históricos vinculados à questão da obesidade.

\section{Considerações Finais}

Neste trabalho relatamos a aplicação de uma proposta de ensino que exigiu de estudantes de graduação em Química a resolução de um caso investigativo estreitamente relacionado à área de Bioquímica. A análise dos relatórios por eles elaborados, nos quais apontam a resolução do caso, indica a aquisição de conhecimentos científicos relevantes e sugere a adequação da aplicação do roteiro que subsidiou a produção dos relatórios.

Tendo em vista o exposto, o presente trabalho corrobora as considerações de pesquisadores da área de Educação em Química com relação à potencialidade da aplicação de casos investigativos na promoção de um ensino de melhor qualidade no nível superior (SÁ \& QUEIROZ, 2010).

\section{Nota}

$1 \mathrm{O}$ grupo disponibiliza gratuitamente um banco de casos investigativos no site $<w w w . g p e q s c . c o m . b r>$

\section{Referências Bibliográficas}

CORNELY, K. "The Use of Case Studies in an Undergraduate Biochemistry Course". Fournal of Chemical Education, vol. 75, n. 4, 1998, p. 475.

HERREID, C. F. "The Case Study: What Makes a Good Case? Some Basic Rules of Good Storytelling Help Teachers Generate Student Excitement in the Classroom". Fournal of College Science Teaching, vol. 27, n. 3, 1997, p. 163.

KORTLAND, K. "An STS Case Study about Students' Decision Making on the Waste Issue". Science Education, vol. 80, n. 6, 1996, p. 673.

MASSI, L.; CERRUTTI. B. M.; QUEIROZ, S. L. "Metodologia de Ensino Jigsaw em Disciplina de Química Medicinal". Química Nova, vol. 36, n. 6, 2013, p. 897.

SÁ, L. P. Estudo de Casos na Promoção da Argumentação sobre Questões Sócio-Científicas no Ensino Superior de Química. Tese (Doutorado em Ciências). Departamento de Química, Universidade Federal de São Carlos, São Carlos, 2010.

SÁ, L. P. \& QUEIROZ, S. L. Estudo de Casos no Ensino de Química. 2. ed. Campinas: Átomo, 2010.

TEODORO, D. L.; PAGOTTO, J. F.; MOTHEO, A. J.; QUEIROZ, S. L. "Formação Docente no Ensino Superior de Química: Contribuições dos Programas de Aperfeiçoamento de Ensino". Química Nova, vol. 34, n. 4, 2011, p. 714.

Publicado em 11/11/2016. 